\title{
Can Nerve Trunks Serve as Railroads for Stem Cells?
}

\author{
Kulchitsky Vladimir ${ }^{1}$, Zamaro Alexandra ${ }^{1}$, Krivenchuk Dmitry ${ }^{1}$, Koulchitsky Stanislav ${ }^{2}$ \\ ${ }^{1}$ Institute of Physiology, National Academy of Sciences, Belarus \\ ${ }^{2}$ Liege University, Belgium \\ *Corresponding author: Kulchitsky Vladimir, Institute of Physiology, National Academy of Sciences, Belarus
}

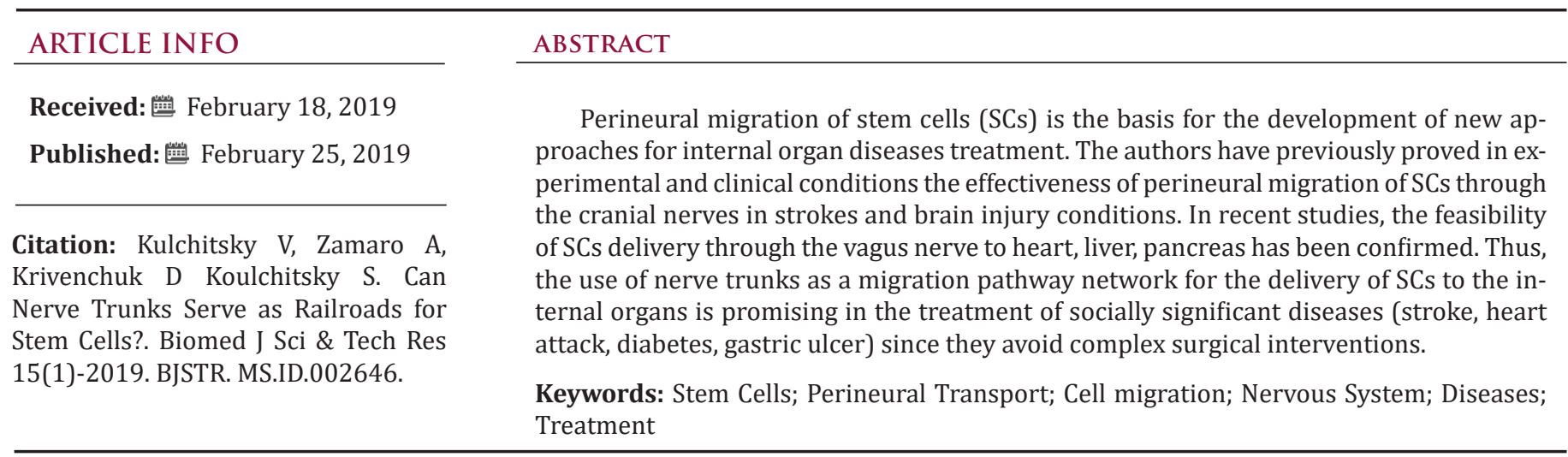

\section{Opinion}

Living organisms undergo natural selection process during evolution. Optimal conditions have been formed for development and coordinated functioning of all structural elements of living organisms. That is for normal development of organisms. In pathology coordination of interactions between systems, organs, and cells is broken. This is important aspect in terms of treatment when qualified medical doctor corrects impaired functions not only at the level of definite organ, where pathological process happened, but at the level of the whole organism to amplify protective reaction. The statement may be supported by known quote that wounds of winners are healing more quickly than those of defeated. Positive emotions of winners are accompanied with release of endorphins, enkephalins and other regulatory factors in bloodstream, which contributes to activation of reparative processes. It is advisable to note that though the above reasoning is informative, but it is not always acceptable in such situations like strokes or brain injuries when integrative brain activity is impaired. Consequently, in each specific clinical situation along with existing international treatment protocols, it is advisable, according to prescriptions, to apply the individualized cell therapy principle to patients. It requires concise combination of local and systematic methods for correction of impaired functions.
To this end, it is advisable first to pay attention to adequacy of the problem of cellular technologies application to initiation of plasticity and reparative processes in damaged tissues and organs. Why so? The current situation with application of cellular technologies describes systematic introduction of stem cells (SCs) as the dominant method in cell therapy of diseases accompanied with violation of structure and function of organs and systems of living organism [1,2]. Also, it is known that SCs hardly overcome histo-hematic barriers [3]. Thus, the blood-brain barrier is an unbreachable obstacle for SCs on their way to areas of destruction in brain $[3,4]$. Therefore, it is necessary to find alternative ways of SCs delivery to brain in addition to classic methods of reparative processes activation in nerve tissue after injury or stroke. Moreover, world statistics shows that classic ways of brain functions restoration are ineffective $[5,6]$. Considering the main ways of drug and SCs delivery to organs and tissues: enteral and parenteral. The attractiveness of enteral way is accessibility, but among the proven deficiencies, the key is destruction of substances and cells in gastrointestinal tract, mainly in liver. Various methods of parenteral administration are used for introduction of stem cells: applications on skin and mucous membranes, injections, inhalations. 


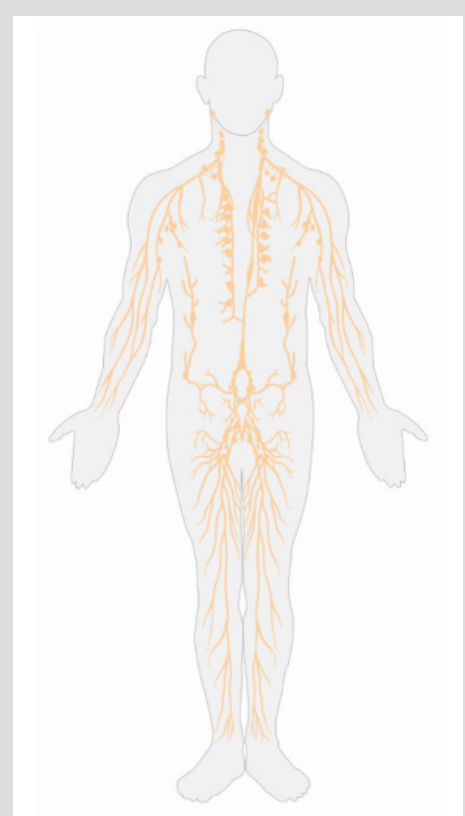

Figure 1: Scheme of the human lymphatic system. Explained in text.
The most commonly used way of systemic administration of SCs is arterial or venous vascular network. In some studies, intraventricular route of SCs [6] was used or even direct application followed by craniotomy to the area of nerve tissue destruction. Introduction of SCs into bloodstream is the most common method due to its availability, but the effectiveness is extremely small, especially to brain. Metabolic products come from tissues through the wall of micro vessels into the bloodstream in circulatory system (Figure 1). Gases, ions, glucose, lipids, proteins and other molecules are exchanged through the wall of micro vessels-mainly capillaries and arterioles. So, in closed systems, blood does not come into direct contact with cells (Figure 1), but at the brain level the blood-brain barrier is an additional obstacle for SCs migration from bloodstream to brain tissue. The obvious disadvantages of intravascular injections of SCs include decrease in concentration due to dilution in about 5 liters of blood. The situation is similar when lymphatic system is used for SCs migration (Figure 2). Figure 2 shows network of lymphatic vessels in human body. The same question arises on the possibility of local effect of SCs after their introduction into lymphatic vessels in the presence of systemic principle of distribution of such vessels (Figure 2).

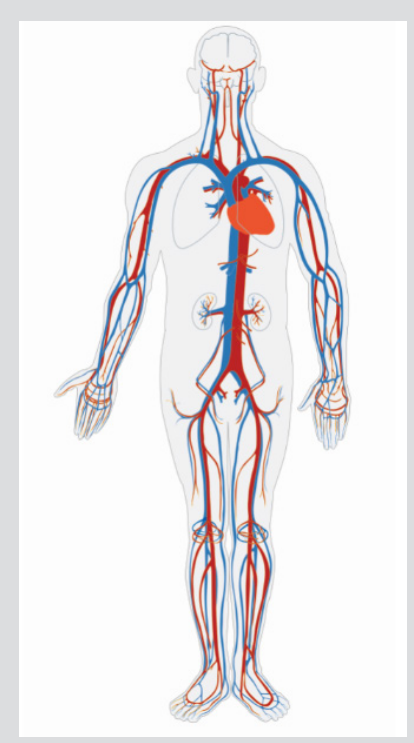

Figure 2: Scheme of the human circulatory system. Recreated under artist permission.

Various methods have been developed to introduce SCs into regional blood [8-10] or lymphatic vessels, for example, into limb veins, arterial and venous vessels of brain. Such method allows performing angiography of brain vessels depending on blood supply of brain regions by internal carotid arteries and vessels of vertebrobasilar basin. By the way, introduction of SCs into bloodstream is generally accepted in comparison with single observations about introduction of SCs into lymphatic system. If we consider Figure 3, which shows central and peripheral parts of nervous system, then a logical conclusion arises on systemic effects when acting on any part of nervous system (Figure 3). Nervous system constantly integrates and processes information from organs and body systems, as well as from external environment to make the most appropriate response decision. But, along with systemic principle of control of the whole organism functions, structure of nervous system is the basis regional processes control. This structural and functional aspect of nervous system activity was the basis for attempt to use cranial nerves as a kind of pathway for SCs to migrate to certain part of nervous system (somatotopic principle) [11,12]. 


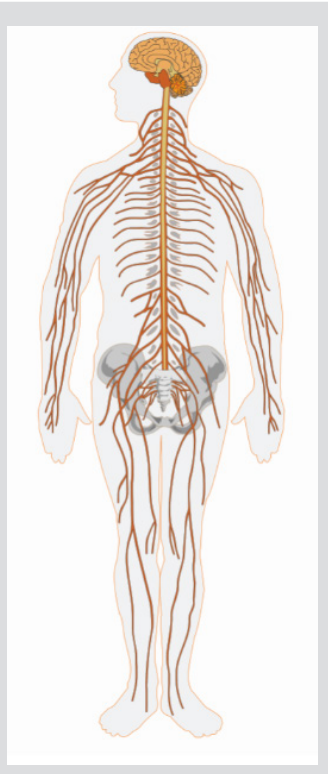

Figure 3: Scheme of the human nervous system. Licensed under Creative Commons 3.0.

Experimental studies [8-12] followed by clinical observations [13-15] proved reality of SCs movement along cranial nerves to specific parts of central nervous system in the presence of destructive processes in the area [13-15]. The pattern of SCs migration to the area of destructive processes was verified in experiments with SCs movement along vagus nerve to damaged areas in internal organs (heart, liver, pancreas, stomach) $[16,17]$. Thus, various parts of nervous system may serve as pathways for targeted movement of SCs into the area of internal organs destruction (Figure 4). Implementation of somatotopic principle of SCs migration to specific receptive fields of somatic or autonomic nerves is the basis for addition of new methodological realities to existing methods of brain diseases (strokes, injuries) treatment. We talk about additional methods of therapy with the help of perineural method of SCs delivery to internal organs via vagus or other nerves to treat patients with pancreatitis, diabetes, heart failure, hepatitis and stomach ulcer. Future research will expand the list of these pathological processes.

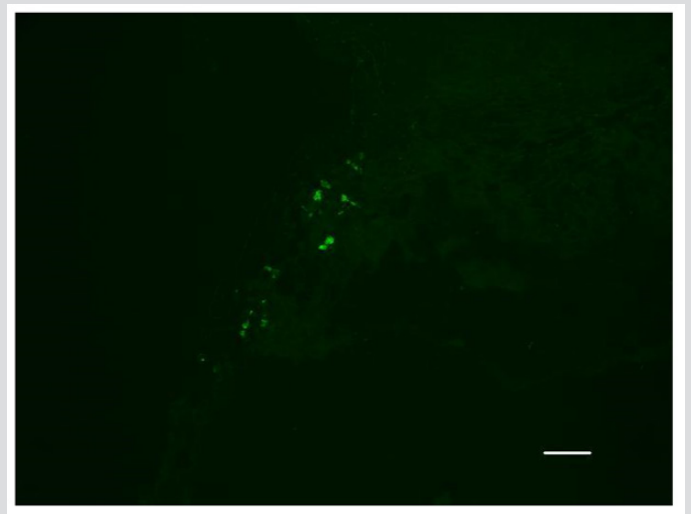

Figure 4: Distribution of PKH67-labeled SCs in the rat liver. Bar - $100 \mu \mathrm{m}$. Explained in text.

\section{Acknowledgement}

This pooled analysis was funded by 000 "Synergy", and by innovative fund of Brest Regional Executive Committee (20172019).

\section{References}

1. Li X, Huang M, Zhao R, Zhao C, Liu Y, et al. (2018) Intravenously Delivered Allogeneic Mesenchymal Stem Cells Bidirectionally Regulate Inflammation and Induce Neurotrophic Effects in Distal Middle Cerebral Artery Occlusion Rats Within the First 7 Days After Stroke. Cell Physiol Biochem 46(5): 1951-1970.

2. Shen WC, Chou YH, Huang HP, Sheen JF, Hung SC, et al. (2018) Induced pluripotent stem cell-derived endothelial progenitor cells attenuate ischemic acute kidney injury and cardiac dysfunction. Stem Cell Res Ther 9(1): 344.

3. Stebbins MJ, Wilson HK, Canfield SG, Qian T, Palecek SP, et al. (2016) Differentiation and characterization of human pluripotent stem cellderived brain microvascular endothelial cells. Methods 101: 93-102.

4. Faezi M, Nasseri Maleki S, Aboutaleb N, Nikougoftar M (2018) The membrane mesenchymal stem cell derived conditioned medium exerts neuroprotection against focal cerebral ischemia by targeting apoptosis. J Chem Neuroanat 94: 21-31.

5. Csöbönyeiová M, Polák Š, Danišovič L (2016) Toxicity testing and drug screening using iPSC-derived hepatocytes, cardiomyocytes, and neural cells. Can J Physiol Pharmacol 94(7): 687-694.

6. Soares Miranda L, Siscovick DS, Psaty BM, Longstreth WT Jr, Mozaffarian D (2016) Physical Activity and Risk of Coronary Heart Disease and Stroke in Older Adults: The Cardiovascular Health Study. Circulation 133(2): 147-155

7. van Velthoven CT, Kavelaars A, van Bel F, Heijnen CJ (2010) Nasal administration of stem cells: a promising novel route to treat neonatal ischemic brain damage. Pediatr Res 68(5): 419-422.

8. Balyasnikova IV, Prasol MS, Ferguson SD, Han Y, Ahmed AU, et al. (2014) Intranasal delivery of mesenchymal stem cells significantly extends survival of irradiated mice with experimental brain tumors. Mol Ther 22(1): 140-148.

9. Sun J, Wei ZZ, Gu X, Zhang JY, Zhang Y, et al. (2015) Intranasal delivery of hypoxia-preconditioned bone marrow-derived mesenchymal stem cells enhanced regenerative effects after intracerebral hemorrhagic stroke in mice. Exp Neurol 272: 78-87.

10. Wei ZZ, Gu X, Ferdinand A, Lee JH, Ji X, et al. (2015) Intranasal delivery of bone marrow mesenchymal stem cells improved neurovascular regeneration and rescued neuropsychiatric deficits after neonatal stroke in rats. Cell Transplant 24(3): 391-402.

11. Kulchitsky V, Zamaro A, Shanko Y, Koulchitsky S (2018) Prospects of Perineural Implantation of Stem Cells in Recovery of Neural Networks' Functions in Brain Diseases. Biomed J Sci \& Tech Res 10(3): 1-4.

12. Kulchitsky V, Zamaro A, Pashkevich S, Sushko T, Koulchitsky S (2018) Nasolacrimal way of stem cells implantation. J Neurol Stroke 8(2): 110111.

13. Kulchitsky V, Zamaro A, Shanko Y, Koulchitsky S (2018) Positive and negative aspects of cell technologies in cerebral diseases. J Neurol Stroke 8(2): 87-88.

14. Shanko Y, Navitskaya V, Zamaro A, Krivenko S, Zafranskaya M, et al. (2018) Prospects of Perineural Administration of Autologous Mesenchymal Stem Cells of Adipose Tissue in Patients with Cerebral Infarction. Biomed J Sci \& Tech Res 10(1): 1-3.

15. Shanko Y, Navitskaya V, Zamaro A, Zafranskaya M, Krivenko S, et al. (2018) Somatotopic principle of perineural implantation of stem cells in patients with brain injuries. J Neurol Stroke 8(5): 259-261. 
16. Zamaro A, Koulchitsky S, Pashkevich S, Stukach Y, Dosina M, et al. (2019) Perineural Way of Stem Cells Migration to Injured Heart Regions. Biomed J Sci \& Tech Res 14 (1): 1-4.

\section{ISSN: 2574-1241}

DOI: 10.26717/BJSTR.2019.15.002646

Kulchitsky Vladimir. Biomed J Sci \& Tech Res

(C) This work is licensed under Creative

Submission Link: https://biomedres.us/submit-manuscript.php
17. Kulchitsky V, Zamaro A, Koulchitsky S (2019) Perineural Migration of Stem Cells in the Model of Damaged Heart Nodes. Biomed J Sci \& Tech Res 14 (4): 1-3.

Assets of Publishing with us
BIOMEDICAL
RESEARCHES
- Global archiving of articles

